\title{
Separation and Recovery of Lithium, Cobalt and Nickel Ion in an Aqueous Phase by Slug Flow
}

\author{
Mikiya HinOuE ${ }^{1}$, Masaki HiRAYAMA ${ }^{1}$, Akinori MUTO ${ }^{1 *}$ \\ ${ }^{1}$ School of Engineering, Osaka Prefecture University, 1-1 Gakuencho, Naka-ku, Sakai 599-8531, Japan
}

\begin{abstract}
Extraction by slug flow gives high mass transfer rate and rapid phase separation than the conventional extraction operation. Therefore, there are many advantages such as the volume of the device becomes small and the solvent drastically reduced. The slug flow extraction is expected as a sophisticated separation process. Especially, these advantages become more prominent in the multistage extraction. In this study, the extraction by the slug flow was applied to mutual separation of lithium, cobalt and nickel ions in the mixed aqueous solution. We succeeded in developing a process with lithium, cobalt, nickel ion purity of $85 \%$ or more and recovery rate of $90-95 \%$. Furthermore, it was also confirmed that the flow state of the liquid is influenced by the hydrophobicity (PTFE) and hydrophilicity (glass) of the extraction tube. The overall mass transfer volumetric coefficient is affected by (1) the interface area of the oil phase and aqueous phase, (2) the strength of the circulating flow in each segment of the liquid, and (3) the volume flow ratio of the oil phase and the aqueous phase.
\end{abstract}

\section{Introduction}

Lithium ion secondary batteries are used as power sources for various devices because of their advantages such as high energy density and long life, and the demands are expected to increase more and more (Xu et al., 2017). For this reason, securing of rare metals, which are raw materials of the positive electrode materials, is an urgent matter, and it is necessary to establish an industrial recycling method to obtain high purity rare metals.

Slug flow, which is one of the micro flow conditions, gives a high mass transfer capacity coefficient. The rapid phase separation of the slug flow is expected to be applied to solvent extraction (Kashid et al., 2007). In this study, we investigate the separation and enrichment of each ion from dilute aqueous solution of cobalt, nickel and lithium by solvent extraction using the slug flow. The flow state was affected by PTFE (hydrophobic) and glass (hydrophilic) as the flow tube material. The influence of the flow state on the mass transfer capacity coefficient was investigated. Furthermore, the extraction rates were predicted using the obtained mass transfer capacity coefficient, and it was examined whether it was possible to set a simple guideline for the device. A study on the extraction of cobalt and lithium ions by single and binary slag flow was reported in the literature (Hirayama et al., 2018). In this study, we investigated ternary mixed solution of cobalt ion, lithium ion and nickel ion. Especially, we focus on cobalt ion.

\section{Experimental}

\footnotetext{
* Corresponding author: amuto@chemeng.osakafu-u.ac.jp
}

$1.0 \mathrm{mM}$ cobalt chloride, nickel chloride, and lithium chloride were dissolved in ion-exchanged water to prepare an aqueous solution as a model leaching solution from a waste lithium ion battery. The solution was separated from each other according to the process (Virolainen et al., 2017) shown in Figure 1. Cobalt and nickel were transferred to the oil phase and lithium was separated and recovered by the extraction step 1 (Loading). As the extractant, a cyclohexane solution of sodium-substituted bis 2-ethylhexyl hydrogen phosphate (D2EHPA-Na) was used. Next, lithium in the oil phase is removed by the washing step 2 in which the oil phase is brought into contact with an aqueous nickel solution Scrubbing). In the back-extraction step 3 (Stripping (Ni)) with dilute sulfuric acid, only nickel was transferred from the oil phase to the aqueous phase. Cobalt ion was recovered with concentrated hydrochloric acid in the back-extraction step 4 (Stripping (Co)). Each element was separated and recovered by this process.

The liquid-liquid contact in each process was carried out by slug flow using the equipment of Figure 2. After liquid-liquid contact, each concentration was measured using an atomic absorption spectrophotometer. Furthermore, the extraction rate $\mathrm{E}[\%]$ and the backextraction rate $\mathrm{S}[\%]$ were defined by Equations (1) and (2). $\mathrm{C}_{0}[\mathrm{mM}]$ is the initial concentration, $\mathrm{C}[\mathrm{mM}]$ is the extract concentration, the subscript $\mathrm{A}$ indicates the concentration in the aqueous phase, and $\mathrm{O}$ indicates the concentration in the oil phase.

By changing the ratio of oil phase volume flow rate $v_{O}$ and water phase volume flow rate $\mathrm{v}_{\mathrm{A}}$ at the time of liquidliquid contact by slug flow, concentration of cobalt ion was performed in forward extraction and back extraction. At this time, the total flow rate of the oil phase and the 
aqueous phase was set to $120 \mathrm{~mL} / \mathrm{h}$. A $30-150 \mathrm{~cm}$ PTFE or glass tube were used for the flow tube. In this experiment, it was confirmed that the water phase and the oil phase flowed in a stable slug flow regardless of whether a glass tube or PTFE tube was used.

$$
\begin{aligned}
& E=\left(\frac{C_{0}-C}{C_{0}}\right)_{\mathrm{A}} \times 100 \\
& S=\left(\frac{C_{0}-C}{C_{0}}\right)_{\mathrm{O}} \times 100
\end{aligned}
$$

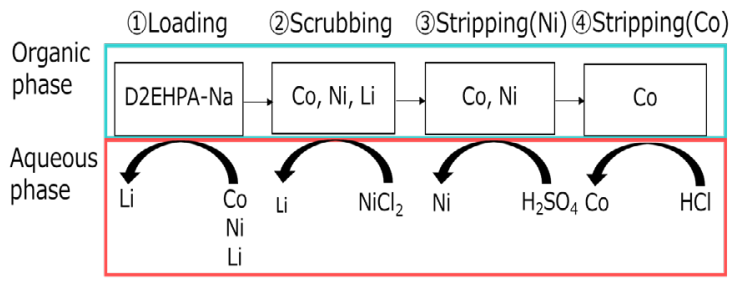

Figure 1 Proposed of flowsheet for solvent extraction in Co, $\mathrm{Ni}$, Li system

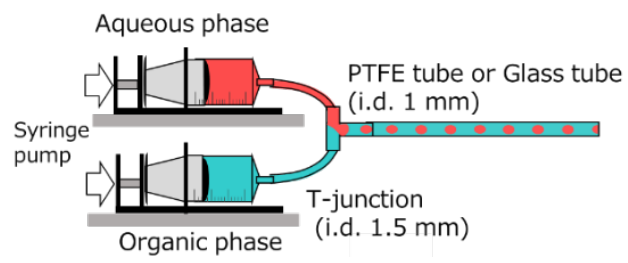

Figue 2 Experimental apparatus of solvent extraction

\section{Results and Discussion}

\subsection{Evaluation of mutual separation of ions}

The yield $\mathrm{Y}_{M}[\%]$ and purity $\mathrm{P}_{M}[\%]$ of each ion recovered to the water phase were evaluated by Equations (3) and (4) and the results are shown in Table 1.

$$
\begin{aligned}
Y_{\mathrm{M}} & =\frac{C_{\mathrm{M}}}{C_{\mathrm{M}, 0}} \times 100 \\
\mathrm{P}_{\mathrm{M}} & =\frac{C_{\mathrm{M}}}{C_{\text {total }}} \times 100
\end{aligned}
$$

$\mathrm{C}_{\mathrm{M}}$ indicates the metal ion concentration corresponding to the subscript, $\mathrm{C}_{\text {total }}$ indicates the total metal ion concentration after separation process shown in Figure 1.

In this experiment, recovery of each ion was achieved at a yield and purity of $80 \%$ or more.

Table 1 Yield and purity of metal ions in the process.

\begin{tabular}{llc}
\hline & $\mathrm{Y}_{\mathrm{M}}[\%]$ & $\mathrm{P}_{\mathrm{M}}[\%]$ \\
\hline Cobalt & 96.7 & 82.2 \\
Nickel & 81.6 & 94.9 \\
Lithium & 86.2 & 94.7 \\
\hline
\end{tabular}

\subsection{Enrichment of cobalt ions by positive extraction}

\subsubsection{Effects of the flow tube material on the forward extraction rate}

An aqueous solution of $110 \mathrm{mM}$ D2EHPA-Na and 1.0 $\mathrm{mM}$ cobalt chloride was passed through a PTFE tube or a glass tube at $v_{A} / v_{O}=1-49$. Figure 3 shows the extraction efficiency at $38 \mathrm{~s}$ of the extraction time. The PTFE tube had a higher extraction rate than the glass tube. The extraction rate decreased with the increase of $v_{A} / v_{O}$. When $v_{A} / v_{O}=49,32$ times concentration of cobalt ion was achieved in 38 seconds.

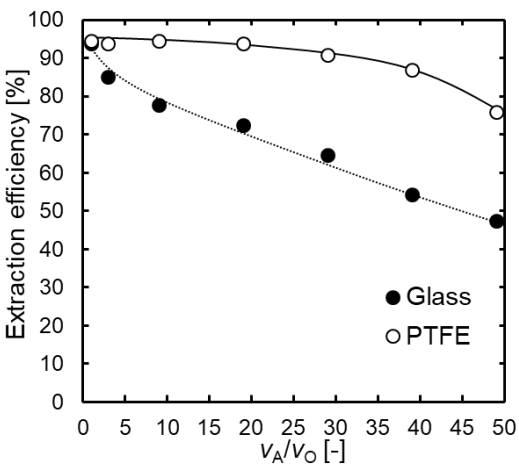

Figure 3 Relationship between extraction efficiency at $38 \mathrm{~s}$ and $\mathrm{VA} / \mathrm{vo}$

\subsubsection{Effects of flow path material on mass transfer}

The overall mass transfer capacity coefficient $\mathrm{k}_{\mathrm{L}} \mathrm{a}$ [s-1] is derived by equation (5) (Kashid et al., 2007). Here, E* is the extraction rate at equilibrium.

$$
-\ln \left(1-\frac{E}{E^{*}}\right)=k_{\mathrm{L}} a t
$$

The specific interface area per liquid volume, $\mathrm{a}\left[\mathrm{m}^{-1}\right]$ and the mass transfer coefficient $\mathrm{k}_{\mathrm{L}}$ [m.s-1]. a is a surface area per unit volume.

Applying this experimental result to Equation (5), a good linear relationship was not obtained between the left side and the contact time $t$. It is suggested that the mixing effects at the junction of the two liquids and at the tube are different. Therefore, it is assumed that this device had different $\mathrm{k}_{\mathrm{L}} \mathrm{a}$ at the junction and in the pipe. The experimental results of $0-15 \mathrm{~s}$, which are the initial stage of extraction, were applied to Equation (5), and $\mathrm{k}_{\mathrm{L}} \mathrm{a}$ at the 
junction was calculated. As for $\mathrm{k}_{\mathrm{L}} \mathrm{a}$ in the tube, the experimental result of 7.2 - $38 \mathrm{~s}$ was calculated by Equation (5).

The derivation results of $\mathrm{k}_{\mathrm{L}} \mathrm{a}$ in the junction and in the tube are shown in Figures 4 and 5. Since $\mathrm{k}_{\mathrm{L}} \mathrm{a}$ at the junction is larger than $\mathrm{k}_{\mathrm{L}} \mathrm{a}$ in the pipe, good mass transfer can be confirmed at the junction. This result suggests that turbulence of the liquid promotes mass transfer at the interface at the junction of the water phase and the oil phase. The PTFE tube had a larger $\mathrm{k}_{\mathrm{L}}$ a than the glass tube. When PTFE tube was used, $\mathrm{k}_{\mathrm{L}}$ a increased while $\mathrm{v}_{\mathrm{A}} / \mathrm{v}_{\mathrm{O}}=$ 1-3 and decreased when $v_{A} / v_{O}=3$ or more. On the other hand, in the case of glass tube, $\mathrm{k}_{\mathrm{L}}$ a decreased as $\mathrm{v}_{\mathrm{A}} / \mathrm{v}_{\mathrm{O}}$ increased.

In the case of a PTFE tube (hydrophobic material), liquid film of the oil phase is formed on the tube wall, and on the other hand, in the case of a glass tube (hydrophilic material), liquid film of the water phase is formed on the tube wall. Since the continuous phase and the dispersed phase are reversed depending on the material of the flow tube, each of specific surface area, a can be obtained by different calculation formulas. When the low flow phase is the continuous phase, a of the low flow phase is calculated by the Equation (6), and when the dispersed phase is the Equation (7).

$$
\begin{aligned}
& a_{\mathrm{C}}=\frac{2 \pi r h_{\mathrm{D}}+2 \pi r^{2}}{\pi r^{2} h_{\mathrm{C}}} \\
& a_{\mathrm{D}}=\frac{2 \pi r h_{\mathrm{D}}+2 \pi r^{2}}{\pi r^{2} h_{\mathrm{D}}}
\end{aligned}
$$

Here, $\mathrm{r}[\mathrm{mm}]$ is the tube radius, $\mathrm{h}[\mathrm{mm}]$ is the slug length, subscript $\mathrm{C}$ represents the continuous phase, and D represents the dispersed phase.

The overall mass transfer coefficient $\mathrm{k}_{\mathrm{L}}$ was calculated by dividing $\mathrm{k}_{\mathrm{L}} \mathrm{a}$ by the calculated $\mathrm{a}$. The effects of $\mathrm{v}_{\mathrm{A}} / \mathrm{v}_{\mathrm{O}}$ on $\mathrm{k}_{\mathrm{L}}$ and a are shown in Figure 6. The specific area, a increased significantly only when the PTFE tube was used. Because, the oil phase forms covered oil film on the tube wall, and the area of the oil phase increases. The value of $\mathrm{k}_{\mathrm{L}}$ decreased with increasing of $\mathrm{v}_{\mathrm{A}} / \mathrm{v}_{\mathrm{O}}$ for both PFFE and glass tubes. As $\mathrm{v}_{\mathrm{A}} / \mathrm{v}_{\mathrm{O}}$ increases, a long-shaped water phase slug was generated. It is thought that $\mathrm{k}_{\mathrm{L}}$ decreased as the diffusion distance increased due to the increase in slug length. Furthermore, $\mathrm{k}_{\mathrm{L}}$ was larger than for the glass tube. Since the strength of circulation flow in the oil phase segment do not change significantly depending on the material of the flow tube, $\mathrm{k}_{\mathrm{L}}$ is considered to give the same value. Therefore, it was found that the reaction at the oil film became slow as the extraction reaction progressed. From the above results, the specific interface area of the oil phase, which is a low flow rate phase, can be greatly improved by using a PTFE tube that forms an oil film on the tube wall.

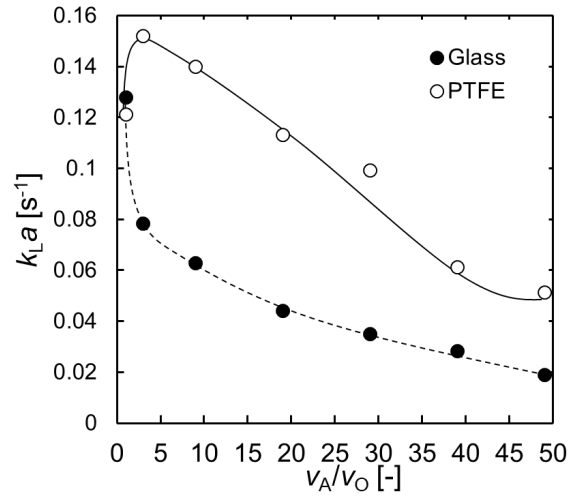

Figure 4 Relationship between $k_{L} a$ of 'at T-junction and $v_{\mathrm{A}} / v_{\mathrm{O}}$ in loading

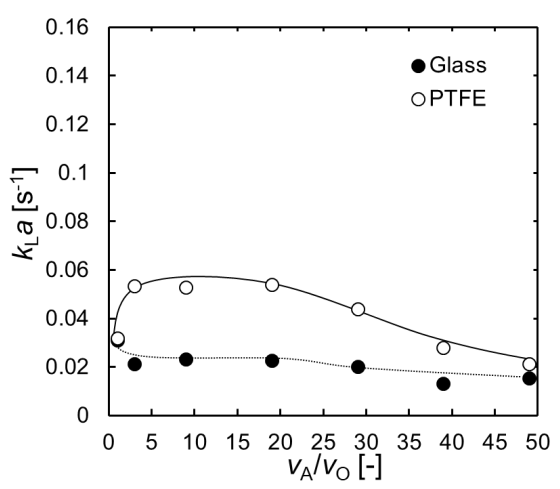

Figure 5 Relationship between $k_{L} a$ of 'in tube' and $v_{\mathrm{A}} / v_{\mathrm{O}}$ in loading

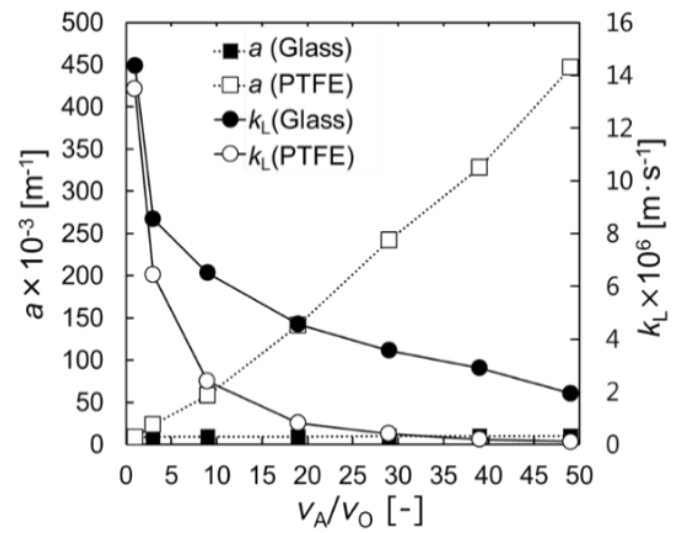

Figure 6 Relationship between $k_{L}, a$ and $v_{\mathrm{A}} / v_{\mathrm{O}}$ in loading.

\subsection{Enrichment of cobalt ions by back extraction}

\subsubsection{Effective of tube material on the back- extraction rate}

The 53.8 mM D2EHPA-Co cyclohexane solution obtained by the forward extraction and $5 \mathrm{M} \mathrm{HCl}$ were flowed through a PTFE tube and a glass tube. Figure 7 
shows the rate of back extraction after contact for 38 seconds. The glass tube gave higher reverse extraction rate than the PTFE tube. In addition, the reverse extraction rate decreased with the increase of $\mathrm{v}_{\mathrm{O}} / \mathrm{v}_{\mathrm{A}}$, but when $\mathrm{v}_{\mathrm{O}} /$ $\mathrm{v}_{\mathrm{A}}=39,34$ times concentration of cobalt ion was achieved in 38 seconds. In the enrichment operation by forward extraction, 32 times concentration of $1 \mathrm{mM}$ cobalt chloride aqueous solution is achieved, and by enrichment by back extraction, it is possible to concentrate $1 \mathrm{mM}$ cobalt chloride aqueous solution nearly 1000 times. The combined operations of the forward and reverse extractions succeeded to enrichment of higher concentration aqueous solution of cobalt chloride suitable for the recycling process.

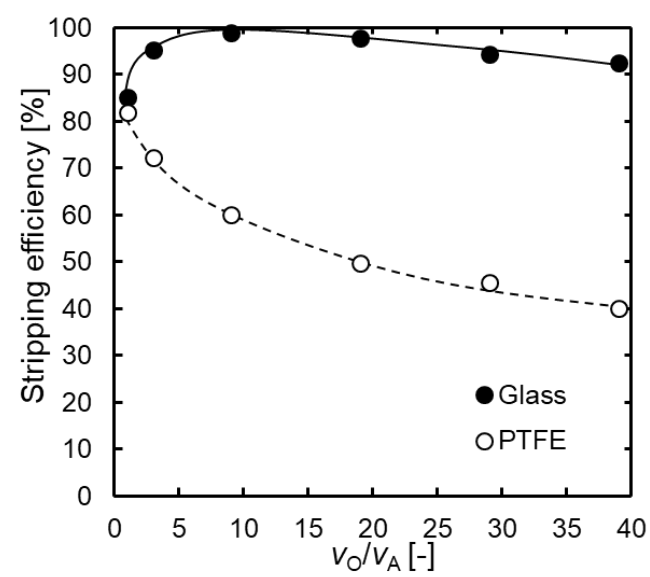

Figure 7 Relationship between stripping efficiency at $38 \mathrm{~s}$ and $v_{\mathrm{O}} / v_{\mathrm{A}}$

\subsubsection{Effects of flow tube material on mass transfer}

The overall mass transfer capacity coefficient in the junction and tube was calculated in the same way as the forward extraction experiment. The results of deriving $\mathrm{k}_{\mathrm{L}} \mathrm{a}$ in the junction and tube are shown in Figures 8 and 9. Since $\mathrm{k}_{\mathrm{L}} \mathrm{a}$ at the junction is larger than that in the tube, good mass transfer can be confirmed at the junction, and the glass tube has larger $\mathrm{k}_{\mathrm{L}}$ a than the PTFE tube. When the glass tubes were used, $\mathrm{k}_{\mathrm{L}}$ a increased while $\mathrm{v}_{\mathrm{O}} / \mathrm{v}_{\mathrm{A}}=1$ 9 and decreased at $v_{O} / v_{A}=9$ or more. On the other hand, when PTFE tube was used, $\mathrm{k}_{\mathrm{L}}$ a decreased as $\mathrm{v}_{\mathrm{O}} / \mathrm{v}_{\mathrm{A}}$ increased. In the case of the back extraction, the specific surface area, a was calculated based on the water phase which is the low flow phase. In the case of the glass tube, $\mathrm{a}$ in the water phase was calculated by the Equations (6) and (7) in the case of the PTFE tube.

The mass transfer coefficient $\mathrm{k}_{\mathrm{L}}\left[\mathrm{m} \cdot \mathrm{s}^{-1}\right]$ was calculated by dividing $\mathrm{k}_{\mathrm{L}}$ a by the specific surface area, a. The effects of $\mathrm{v}_{\mathrm{O}} / \mathrm{v}_{\mathrm{A}}$ on $\mathrm{k}_{\mathrm{L}}$ and a are shown in Figure 10. When a glass tube was used, the specific surface area, a increased significantly. Furthermore, $\mathrm{k}_{\mathrm{L}}$ is larger in PTFE, and the opposite result to the positive extraction experiment was obtained. As $\mathrm{v}_{\mathrm{O}} / \mathrm{v}_{\mathrm{A}}$ increases, it is thought that $\mathrm{kL}$ decreases as $v_{O} / v_{A}$ increases monotonously as $v_{O} / v_{A}$ increases. By using a glass tube that forms an aqueous phase film for the back-extraction, the specific interface area of hydrochloric acid increases, and efficient liquidliquid contact was possible.

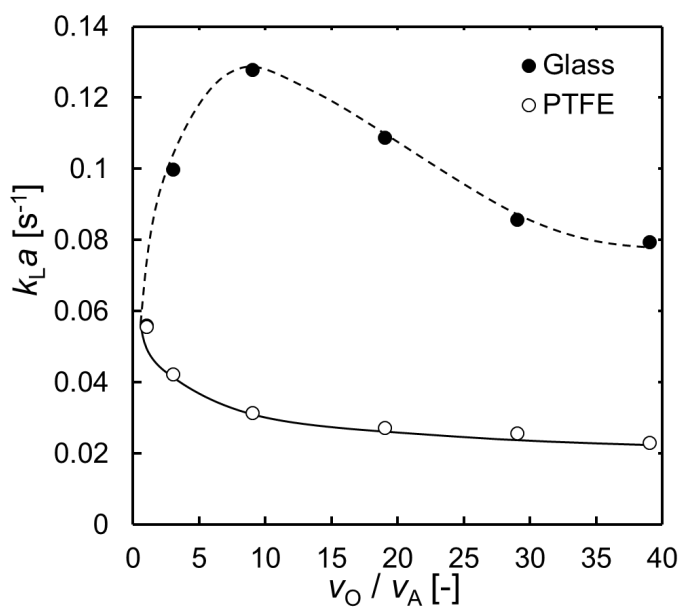

Figure 8 Relationship between $k \mathrm{~L} a$ of T-junction and $v_{\mathrm{O}} / v_{\mathrm{A}}$ in stripping

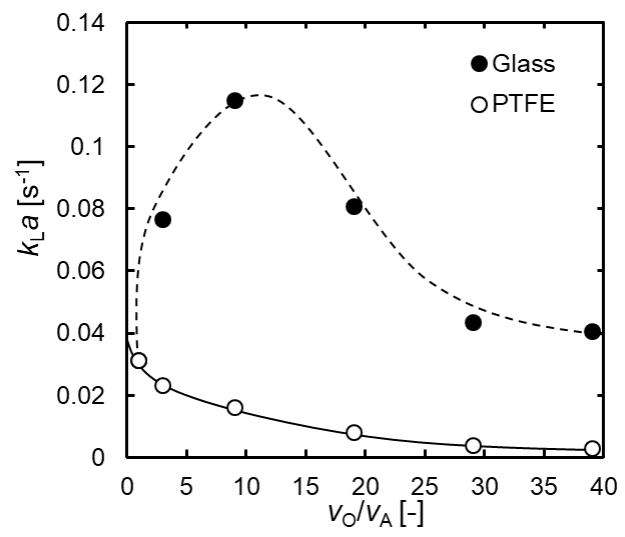

Figure 9 Relationship between $k\left\llcorner a\right.$ of tube and $v_{\mathrm{O}} / v_{\mathrm{A}}$ in stripping

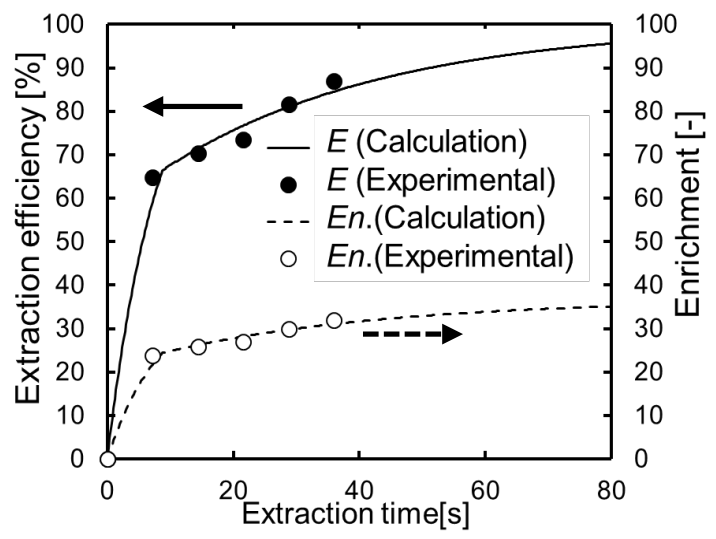

Figure 10 Relationship between $k_{L}, a$ and $v_{\mathrm{O}} / v_{\mathrm{A}}$ in stripping 


\subsection{Prediction of the extraction rate by calculation}

Simple prediction of the concentration operation was performed from the calculated mass transfer capacity coefficient. The mass transfer rate $\mathrm{N}_{\mathrm{A}}\left[\mathrm{mol} \cdot \mathrm{L}^{-1} \cdot \mathrm{s}^{-1}\right]$ of cobalt ion is represented by the Equation (8) (Kashid et al., 2007).

$$
N_{\mathrm{A}}=\frac{d C}{d t}=-k_{\mathrm{L}} a\left(C^{*}-C\right)
$$

Equation ( 8 ') is obtained by Equation (8).

$$
\begin{aligned}
& C(t+\Delta t) \\
& =C(t)-k_{\mathrm{L}} a\left(C^{*}-C\right) \times \Delta t
\end{aligned}
$$

$\mathrm{C}^{*}$ is the cobalt ion concentration at the extraction equilibrium. The change of cobalt ion concentration was determined from the initial concentration and mass transfer capacity coefficient, and the extraction rate and enrichment were calculated respectively. The mass transfer capacity coefficient to be applied to the equation $(8$ ') was used in two types in the junction and in the tube, and the switching time was determined from the intersection of the Equation (5). Figure 11 shows a comparison of measured values and predicted values for the extraction rate and enrichment of forward extraction at $\mathrm{v}_{\mathrm{A}} / \mathrm{v}_{\mathrm{O}}=39$. The experimental results and the calculated results are highly correlated. Enrichment shows how many times concentration has been achieved from the initial concentration. It was found that simple prediction of extraction rate and concentration (enrichment) were possible by the mass transfer capacity coefficient obtained in this experiment.

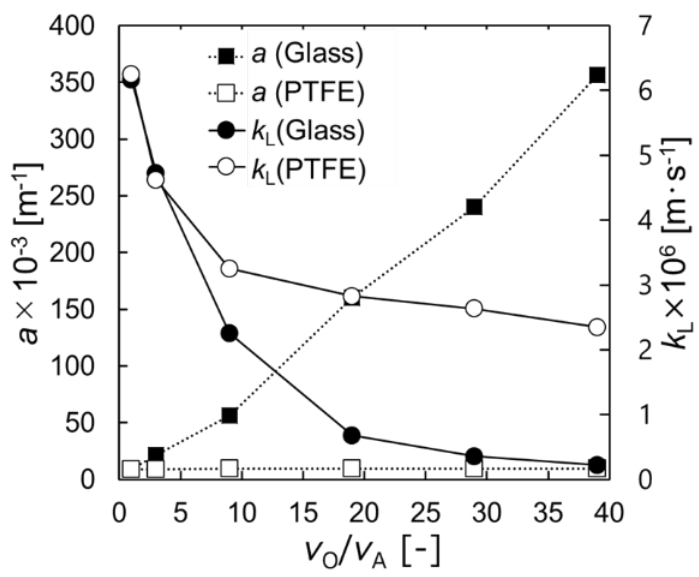

Figure 11 Relationship between extraction efficiency, enrichment and extraction time $\left(\mathrm{v}_{\mathrm{A}} / \mathrm{v}_{\mathrm{O}}=39\right)$
We investigate the separation recovery and enrichment of ions from aqueous solution by combination and forward back extraction by slug flow. The following remarks were obtained;

(1) Each metal ion was recovered at a yield and purity of $80 \%$ or more by multiple liquid-liquid contact processes.

(2) By selecting the appropriate channel material for each process, cobalt ions could be concentrated from the initial concentration to nearly 1000 times by liquidliquid contact for a total of $76(=38 \times 2)$ seconds.

(3) A high correlation was obtained between the measured and calculated values.

\section{Acknowledgements}

This research is supported by the Matching Planner Program from Japan Science and Technology Agency (JST)

\section{References}

Hirayama, Y., M. Hinoue, H. Tokumoto, A. Matusoka, K. Noishiki, and A. Muto ; "Liquid-Liquid Extraction and Separation of Cobalt and Lithium Ions Using a Slug Flow Microreactor," J. Chem. Eng. Japan, 51, 222-228 (2018)

Kashid, M. N., Y. M. Harshe, and D. W.

Agar ; "Liquid-Liquid Slug Flow in a Capillary: An

Alternative to Suspended Drop or Film Contactors," Ind. Eng. Chem. Res., 46, 8420-8430 (2007)

Virolainen, S., M. F. Fini, A. Laitinen, and T. Sainio; "Solvent Extraction Fractionation of Li-ion Battery Leachate Containing Li, Ni, and Co," Sep. Purif. Technol., 179, 274-282 (2017)

Xu, C. and T. Xie; "Review of Microfluidic Liquid-Liquid Extractors," Ind. Eng. Chem. Res., 56, 7593-7622 (2017)

\section{Conclusion}

